\title{
STABILISASI SISTEM KONTROL LINIER DENGAN PENEMPATAN NILAI EIGEN
}

\author{
FAURI \\ Program Studi Matematika, \\ Fakultas Matematika dan Ilmu Pengetahuan Alam, Universitas Andalas, \\ Kampus UNAND Limau Manis Padang, Indonesia, \\ fauri73@rocketmail.com
}

\begin{abstract}
Abstrak. Salah satu kajian dalam sistem kontrol linier adalah mengenai kestabilan sistem tersebut. Sistem $\dot{\mathbf{x}}=A \mathbf{x}+B \mathbf{u}$ adalah stabil jika bagian riil dari semua nilai eigen matriks $A$ adalah negatif. Sebaliknya, jika ada bagian riil matriks $A$ yang non negatif maka sistem $\dot{\mathbf{x}}=A \mathbf{x}+B \mathbf{u}$ adalah tidak stabil. Dalam penelitian ini dikaji tentang proses stabilisasi sistem kontrol linier dengan penempatan nilai eigen. Sistem $\dot{\mathbf{x}}=A \mathbf{x}+B \mathbf{u}$ yang tidak stabil dikatakan dapat distabilkan jika terdapat kontrol $\mathbf{u}=$ $-F \mathbf{x}$ sedemikian sehinggga sistem loop tertutup $\dot{\mathbf{x}}=(A-B F) \mathbf{x}$ adalah stabil, artinya matriks $F$ dipilih sedemikian sehingga bagian riil dari semua nilai eigen matriks $A-$ $B F$ adalah negatif. Dengan teorema yang diberikan, diperoleh syarat yang menjamin eksistensi matriks feedback $F$ sedemikian sehingga sistem $\dot{\mathbf{x}}=(A-B F) \mathbf{x}$ adalah stabil, tetapi nilai eigen dari matriks $A-B F$ dapat diatur sesuai keinginan. Suatu contoh diberikan untuk mengilustrasikan proses stabilisasi ini.
\end{abstract}

Kata Kunci: Penempatan nilai eigen, kestabilan sistem linier

\section{Pendahuluan}

Diberikan sistem kontrol linier sebagai berikut:

$$
\dot{\mathbf{x}}=A \mathbf{x}+B \mathbf{u}, \quad \mathbf{x}(0)=\mathbf{x}_{0},
$$

di mana $\mathbf{x}=\mathbf{x}(t) \in \mathbb{R}^{n}$ menyatakan vektor keadaan (state), $\mathbf{u}=\mathbf{u}(t) \in \mathbb{R}^{m}$ menyatakan vektor kontrol (input), $A \in \mathbb{R}^{n \times n}$ menyatakan matriks konstan berukuran $n \times n, B \in \mathbb{R}^{n \times m}$ menyatakan matriks konstan berukuran $n \times m$ dan $t \geq 0$ menyatakan waktu. Jika matriks $A$ dan $B$ bergantung terhadap waktu, maka sistem (1.1) disebut sistem kontrol linier varying waktu. Sebaliknya, jika matriks $A$ dan $B$ tidak bergantung terhadap waktu, maka sistem (1.1) disebut sistem kontrol linier invariant waktu.

Salah satu kajian dalam sistem kontrol adalah mengenai kestabilan sistem tersebut. Sistem (1.1) dikatakan stabil jika $t \rightarrow \infty$ mengakibatkan $\mathbf{x}(t) \rightarrow 0$. Selain itu kriteria untuk menentukan kestabilan sistem (1.1) adalah kriteria nilai eigen. Sistem (1.1) adalah stabil jika bagian riil dari semua nilai eigen matriks $A$ adalah negatif. Sebaliknya jika ada bagian rill matriks $A$ yang non negatif maka sistem (1.1) adalah tidak stabil [5]. Tidak semua sistem kontrol linier bersifat stabil, akan tetapi sistem yang tidak stabil ini masih memungkinkan untuk distabilkan. 
Sistem (1.1) yang tidak stabil dikatakan dapat distabilkan jika terdapat kontrol $\mathbf{u}=-F \mathbf{x}$ untuk suatu $F \in \mathbb{R}^{m \times n}$ sedemikian sehingga sistem loop tertutup $\dot{\mathbf{x}}=$ $(A-B F) \mathbf{x}$ adalah stabil, artinya matriks $F$ dipilih sedemikian sehingga bagian riil dari semua nilai eigen matriks $A-B F$ adalah negatif. Matriks $F$ disebut matriks feedback dan vektor $\mathbf{u}$ dikatakan kontrol yang menstabilkan sistem (1.1).

Persoalan menjadi menarik jika nilai eigen dari matriks $A-B F$ dapat diatur sesuai keinginan. Berdasarkan uraian diatas, maka dalam penelitian ini akan dikaji bagaimana syarat yang menjamin eksistensi matriks $F$ sedemikian sehingga sistem $\dot{\mathbf{x}}=(A-B F) \mathbf{x}$ adalah stabil, tetapi nilai eigen dari matriks $A-B F$ dapat diatur sesuai keinginan. Permasalahan seperti ini disebut sebagai masalah penempatan nilai eigen.

\section{Stabilisasi Sistem Kontrol Linier dengan Penempatan Nilai Eigen}

Perhatikan kembali sistem kontrol linier (1.1) dan asumsikan bahwa sistem tersebut terkontrol keadaan lengkap dan terdapat suatu kontrol $\mathbf{u}=-F \mathbf{x}$ untuk suatu $F \in \mathbb{R}^{m \times n}$ sedemikian sehingga sistem loop tertutup

$$
\dot{\mathbf{x}}=(A-B F) \mathbf{x}
$$

adalah stabil.

Misalkan $\lambda_{i}, i=1,2, \cdots, n$ adalah nilai eigen yang diinginkan dari matriks $A-$ $B F$. Selanjutnya akan dipelajari karakteristik dari matriks $F$ sedemikian sehingga $\lambda_{i}, i=1,2, \cdots, n$ merupakan nilai eigen dari matriks $A-B F$. Karena $\lambda_{i}$ adalah nilai eigen dari matriks $A-B F$, maka terdapat vektor eigen $\mathbf{v}_{i}$ yang terkait dengan nilai eigen $\lambda_{i}$ sedemikian sehingga

$$
(A-B F) \mathbf{v}_{i}=\lambda_{i} \mathbf{v}_{i}, \quad i=1,2, \cdots, n .
$$

Misalkan $\mathbf{q}_{i}=F \mathbf{v}_{i}$, maka (2.2) dapat ditulis menjadi

$$
\left[\begin{array}{lll}
\lambda_{i} I-A & B
\end{array}\right]\left[\begin{array}{l}
\mathbf{v}_{i} \\
\mathbf{q}_{i}
\end{array}\right]=\mathbf{0}, \quad i=1,2, \cdots, n .
$$

Karena sistem (1.1) adalah terkontrol keadaan lengkap, maka berlaku

$$
\operatorname{rank}\left[\lambda_{i} I-A B\right]=n, \quad \forall \lambda_{i}, i=1,2, \cdots, n .
$$

Hubungan (2.3) memperlihatkan vektor

$$
\left[\begin{array}{l}
\mathbf{v}_{i} \\
\mathbf{q}_{i}
\end{array}\right] \in \operatorname{ker}\left[\lambda_{i} I-A B\right],
$$

oleh karena itu untuk menentukan $F$ sedemikian sehingga $\lambda_{i}, i=1,2, \cdots, n$ merupakan nilai eigen dari matriks $A-B F$, perlu ditentukan suatu basis untuk $\operatorname{ker}\left[\lambda_{i} I-A B\right]$, di mana dimensi dari basis tersebut adalah $(n+m)-$ $\operatorname{rank}\left[\lambda_{i} I-A B\right]=(n+m)-n=m$. 
Misalkan

$$
M^{i}=\left[\begin{array}{cccc}
b_{11}^{i} & b_{12}^{i} & \cdots & b_{1 m}^{i} \\
b_{21}^{i} & b_{22}^{i} & \cdots & b_{2 m}^{i} \\
\vdots & \vdots & & \vdots \\
b_{n 1}^{i} & b_{n 2}^{i} & \cdots & b_{n m}^{i}
\end{array}\right] \quad \text { dan } D^{i}=\left[\begin{array}{cccc}
c_{11}^{i} & c_{12}^{i} & \cdots & c_{1 m}^{i} \\
c_{21}^{i} & c_{22}^{i} & \cdots & c_{2 m}^{i} \\
\vdots & \vdots & & \vdots \\
c_{m 1}^{i} & c_{m 2}^{i} & \cdots & c_{m m}^{i}
\end{array}\right], \quad i=1,2, \cdots, n .
$$

adalah matriks-matriks sedemikian sehingga kolom-kolom dari matriks

$$
Y^{i}=\left[\begin{array}{c}
M^{i} \\
D^{i}
\end{array}\right]
$$

merupakan suatu basis untuk ker $\left[\lambda_{i} I-A B\right]$. Akibatnya

$$
\left[\lambda_{i} I-A B\right]\left[\begin{array}{c}
M^{i} \\
D^{i}
\end{array}\right]=0, \quad i=1,2, \cdots, n \text {. }
$$

Karena $\left[\begin{array}{l}\mathbf{v}_{i} \\ \mathbf{q}_{i}\end{array}\right] \in \operatorname{ker}\left[\lambda_{i} I-A B\right]$, , maka terdapat vektor tak nol

$$
\mathbf{r}_{i}=\left[r_{i 1} r_{i 2} \cdots r_{i m}\right]^{T}, i=1,2, \cdots, n
$$

sedemikian sehingga

$$
\begin{aligned}
& {\left[\begin{array}{c}
\mathbf{v}_{i} \\
\mathbf{q}_{i}
\end{array}\right]=r_{i 1}\left[\begin{array}{c}
b_{11}^{i} \\
b_{21}^{i} \\
\vdots \\
b_{n 1}^{i} \\
c_{11}^{i} \\
c_{21}^{i} \\
\vdots \\
c_{m 1}^{i}
\end{array}\right]+r_{i 2}\left[\begin{array}{c}
b_{12}^{i} \\
b_{22}^{i} \\
\vdots \\
b_{n 2}^{i} \\
c_{12}^{i} \\
c_{22}^{i} \\
\vdots \\
c_{m 2}^{i}
\end{array}\right]+\cdots+r_{i m}\left[\begin{array}{c}
b_{1 m}^{i} \\
b_{2 m}^{i} \\
\vdots \\
b_{n m}^{i} \\
c_{1 m}^{i} \\
c_{2 m}^{i} \\
\vdots \\
c_{m m}^{i}
\end{array}\right]} \\
& =\left[\begin{array}{cccc}
b_{11}^{i} & b_{12}^{i} & \cdots & b_{1 m}^{i} \\
b_{21}^{i} & b_{22}^{i} & \cdots & b_{2 m}^{i} \\
\vdots & \vdots & & \vdots \\
b_{n 1}^{i} & b_{n 2}^{i} & \cdots & b_{n m}^{i} \\
c_{11}^{i} & c_{12}^{i} & \cdots & c_{1 m}^{i} \\
c_{21}^{i} & c_{22}^{i} & \cdots & c_{2 m}^{i} \\
\vdots & \vdots & & \vdots \\
b_{m 1}^{i} & b_{m 2}^{i} & \cdots & b_{m m}^{i}
\end{array}\right]\left[\begin{array}{c}
r_{i 1} \\
r_{i 2} \\
\vdots \\
r_{i m}
\end{array}\right] \\
& =\left[\begin{array}{c}
M^{i} \\
D^{i}
\end{array}\right] r_{i} .
\end{aligned}
$$

Dari (2.6) diperoleh hubungan berikut

$$
\begin{aligned}
& \mathbf{v}_{i}=M^{i} \mathbf{r}_{i}, \quad i=1,2, \cdots, n, \\
& \mathbf{q}_{i}=D^{i} \mathbf{r}_{i}, \quad i=1,2, \cdots, n .
\end{aligned}
$$


Dengan mensubstitusikan $\mathbf{q}_{i}=F \mathbf{v}_{i}$ ke (2.8), maka diperoleh

$$
F \mathbf{v}_{i}=D^{i} \mathbf{r}_{i} \quad i=1,2, \cdots, n,
$$

dan dengan menggunakan (2.7), diperoleh

$$
F M^{i} \mathbf{r}_{i}=D^{i} \mathbf{r}_{i}, i=1,2, \cdots, n .
$$

Jadi, jika sistem (1.1) terkontrol keadaan lengkap dan matriks $F$ dipilih sedemikian sehingga $F$ memenuhi (2.10) maka $\lambda_{i}, i=1,2, \cdots, n$ merupakan nilai eigen dari matriks $A-B F$. Dengan demikian nilai-nilai eigen $A-B F$ dapat diatur sesuai keinginan dengan memilih matriks feedback $F$ yang memenuhi (2.10).

Teorema 2.1. [2] Misalkan sistem (1.1) adalah terkontrol keadaan lengkap. $\left(\lambda_{i}, \mathbf{v}_{i}\right)$ adalah suatu pasangan nilai eigen dan vektor eigen dari $A-B F$ jika dan hanya jika $F$ memenuhi (2.10) untuk suatu vektor tak nol $\mathbf{r}_{i}$ sedemikian sehingga

$$
\boldsymbol{v}_{i}=M^{i} \boldsymbol{r}_{i} \text { dan } \boldsymbol{q}_{i}=D^{i} \boldsymbol{r}_{i},
$$

di mana kolom-kolom dari matriks $\left[\begin{array}{c}M^{i} \\ D^{i}\end{array}\right]$ merupakan suatu basis untuk $\operatorname{ker}\left[\lambda_{i} I-A B\right]$.

Bukti. $(\Rightarrow)$ Telah dibuktikan.

$(\Leftarrow)$ Dengan mengalikan $\lambda_{i} I-(A-B F)$ dengan $M^{i} \mathbf{r}_{i}$, diperoleh

$$
\begin{aligned}
{\left[\lambda_{i} I-(A-B F)\right] M^{i} \mathbf{r}_{i} } & =\left[\lambda_{i} I-A\right] M^{i} \mathbf{r}_{i}+B F M^{i} \mathbf{r}_{i} \\
& =\left[\lambda_{i} I-A\right] M^{i} \mathbf{r}_{i}+B D^{i} \mathbf{r}_{i} \\
& =\left[\lambda_{i} I-A B\right]\left[\begin{array}{c}
M^{i} \\
D^{i}
\end{array}\right] \mathbf{r}_{i} .
\end{aligned}
$$

Dengan menggunakan (2.5), diperoleh

$$
\left[\lambda_{i} I-(A-B F)\right] \mathbf{v}_{i}=\mathbf{0} .
$$

Persamaan (2.11) menunjukkan bahwa $\lambda_{i}, i=1,2, \cdots, n$ merupakan nilai eigen dari matriks $A-B F$ dan $\mathbf{v}_{i}$ adalah vektor eigen yang terkait dengan nilai eigen $\lambda_{i}$.

Jika hubungan (2.10) dituliskan untuk nilai-nilai eigen $\lambda_{i}, i=1,2, \cdots, n$ yang diinginkan, di mana $\mathbf{r}_{i}$ dipilih sedemikian sehingga vektor-vektor eigen $\mathbf{v}_{i}=M^{i} \mathbf{r}_{i}$ yang berkaitan dengan nilai-nilai eigen $\lambda_{i}$ adalah bebas linier, maka

$$
F V=Q,
$$

di mana

$$
V=\left[M^{i} \mathbf{r}_{1} \cdots M^{n} \mathbf{r}_{n}\right]=\left[\begin{array}{lll}
\mathbf{v}_{1} & \cdots & \mathbf{v}_{n}
\end{array}\right]
$$

dan

$$
Q=\left[\begin{array}{lll}
D^{i} \mathbf{r}_{1} \cdots & D^{n} \mathbf{r}_{n}
\end{array}\right]=\left[\begin{array}{lll}
\mathbf{q}_{1} \cdots & \mathbf{q}_{n}
\end{array}\right]
$$


Jika $\lambda_{i}$ berbeda, di mana $i=1,2, \cdots, n$, selalu mungkin untuk memilih $\mathbf{r}_{i}$ sesuai keinginan sedemikian sehingga $V$ adalah full rank. Selanjutnya, matriks feedback $F$ dapat ditentukan oleh persamaan

$$
F=Q V^{-1}
$$

Contoh berikut mengilustrasikan proses stabilisasi sistem kontrol linier dengan penempatan nilai eigen. Diberikan suatu sistem sebagai berikut

$$
\dot{\mathbf{x}}(t)=A \mathbf{x}(t)+B \mathbf{u}(t)
$$

dengan

$$
A=\left[\begin{array}{ccc}
-1 & 0 & 1 \\
-2 & 2 & -2 \\
-1 & 0 & 3
\end{array}\right] \text { dan } B=\left[\begin{array}{cc}
1 & 0 \\
0 & 2 \\
-1 & 1
\end{array}\right]
$$

Dengan menggunakan program MATLAB, diperoleh

$$
\operatorname{rank}\left[B A B A^{2} B\right]=3 \text {. }
$$

Karena matriks keterkontrolan adalah full rank maka sistem (2.16) terkontrol keadaan lengkap. Misalkan nilai-nilai eigen yang diinginkan adalah $\lambda_{1}=-1, \lambda_{2}$ $=-1+j$, dan $\lambda_{3}=-1-j$, maka

$$
\begin{aligned}
& {\left[\lambda_{1} I-A B\right]=\left[\begin{array}{ccccc}
0 & 0 & -1 & 1 & 0 \\
2 & -3 & 2 & 0 & 2 \\
1 & 0 & -4 & -1 & 1
\end{array}\right]} \\
& {\left[\lambda_{2} I-A B\right]=\left[\begin{array}{ccccc}
j & 0 & -1 & 1 & 0 \\
2-3+j & 2 & 0 & 2 \\
1 & 0 & -4+j & -1 & 1
\end{array}\right]} \\
& {\left[\lambda_{3} I-A B\right]=\left[\begin{array}{ccccc}
-j & 0 & -1 & 1 & 0 \\
2 & -3-j & 2 & 0 & 2 \\
1 & 0 & -4-j & -1 & 1
\end{array}\right]}
\end{aligned}
$$

Karena $\operatorname{rank}\left[\lambda_{i} I-A B\right]=3$, di mana $i=1,2,3$, maka diperoleh

$$
Y^{1}=\left[\begin{array}{cc}
0.7944 & -0.2718 \\
0.5669 & 0.4507 \\
0.1417 & 0.1127 \\
0.1417 & 0.1127 \\
-0.0857 & 0.8352
\end{array}\right]
$$

sehingga

$$
M^{1}=\left[\begin{array}{cc}
0.7944 & -0.2718 \\
0.5669 & 0.4507 \\
0.1417 & 0.1127
\end{array}\right]
$$

dan

$$
D^{1}=\left[\begin{array}{cc}
0.1417 & 0.1127 \\
-0.0857 & 0.8352
\end{array}\right]
$$




$$
Y^{2}=\left[\begin{array}{cc}
0.3555+0.5814 i & -0.1404-0.0885 i \\
.0730+0.4226 i & 0.5166+0.0945 i \\
-0.0680+0.1475 i & 0.1546-0.0170 i \\
0.5134-0.2080 i & 0.0661+0.1233 i \\
0.0333-0.1314 i & 0.8079-0.0110 i
\end{array}\right]
$$

sehingga

$$
M^{2}=\left[\begin{array}{cc}
0.3555+0.5814 i & -0.1404-0.0885 i \\
0.0730+0.4226 i & 0.5166+0.0945 i \\
-0.0680+0.1475 i & 0.1546-0.0170 i
\end{array}\right]
$$

dan

$$
D^{2}=\left[\begin{array}{cc}
0.5134-0.2080 i & 0.0661+0.1233 i \\
0.0333-0.1314 i & 0.8079-0.0110 i
\end{array}\right]
$$

Selain itu,

$$
Y^{3}=\left[\begin{array}{cc}
0.3555-0.5814 i & -0.1404+0.0885 i \\
0.0730-0.4226 i & 0.5166-0.0945 i \\
-0.0680-0.1475 i & 0.1546+0.0170 i \\
0.5134+0.2080 i & 0.0661-0.1233 i \\
0.0333+0.1314 i & 0.8079+0.0110 i
\end{array}\right]
$$

sehingga

$$
M^{3}=\left[\begin{array}{cc}
0.3555-0.5814 i & -0.1404+0.0885 i \\
0.0730-0.4226 i & 0.5166-0.0945 i \\
-0.0680-0.1475 i & 0.1546+0.0170 i
\end{array}\right]
$$

dan

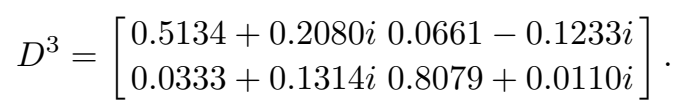

Pilih $\mathbf{r}_{1}=\left[\begin{array}{l}1 \\ 0\end{array}\right], \mathbf{r}_{2}=\left[\begin{array}{l}1 \\ 1\end{array}\right], \mathbf{r}_{3}=\left[\begin{array}{l}1 \\ 1\end{array}\right]$, maka diperoleh

$$
\begin{aligned}
\mathbf{v}_{1} & =M^{1} \mathbf{r}_{1} \\
& =\left[\begin{array}{cc}
0.3555+0.5814 i & -0.1404-0.0885 i \\
0.0730+0.4226 i & 0.5166+0.0945 i \\
-0.0680+0.1475 i & 0.1546-0.0170 i
\end{array}\right]\left[\begin{array}{l}
1 \\
0
\end{array}\right] \\
& =\left[\begin{array}{c}
0.7944 \\
0.5669 \\
0.1417
\end{array}\right] .
\end{aligned}
$$




$$
\begin{aligned}
\mathbf{v}_{2} & =M^{2} \mathbf{r}_{2} \\
& =\left[\begin{array}{cc}
0.3555+0.5814 i & -0.1404-0.0885 i \\
0.0730+0.4226 i & 0.5166+0.0945 i \\
-0.0680+0.1475 i & 0.1546-0.0170 i
\end{array}\right]\left[\begin{array}{l}
1 \\
1
\end{array}\right] \\
& =\left[\begin{array}{c}
0.2151+0.4929 i \\
0.5896+0.5171 i \\
0.0866+0.1305 i
\end{array}\right] . \\
\mathbf{v}_{3} & =M^{3} \mathbf{r}_{3} \\
& =\left[\begin{array}{cc}
0.3555-0.5814 i & -0.1404+0.0885 i \\
0.0730-0.4226 i & 0.5166-0.0945 i \\
-0.0680-0.1475 i & 0.1546+0.0170 i
\end{array}\right]\left[\begin{array}{l}
1 \\
1
\end{array}\right] \\
& =\left[\begin{array}{c}
0.2151-0.4929 i \\
0.5896-0.5171 i \\
0.0866-0.1305 i
\end{array}\right] .
\end{aligned}
$$

Selanjutnya substitusikan $\mathbf{v}_{1}, \mathbf{v}_{2}$, dan $\mathbf{v}_{3}$ ke (2.13), diperoleh

$$
V=\left[\begin{array}{ccc}
0.7944 & 0.2151+0.4929 i & 0.2151-0.4929 i \\
0.5669 & 0.5896+0.5171 i & 0.5896-0.5171 i \\
0.1417 & 0.0866+0.1305 i & 0.0866-0.1305 i
\end{array}\right] .
$$

Dengan menggunakan (2.8), diperoleh

$$
\begin{aligned}
& \mathbf{q}_{1}=\left[\begin{array}{cc}
0.1417 & 0.1127 \\
-0.0857 & 0.8352
\end{array}\right]\left[\begin{array}{l}
1 \\
0
\end{array}\right] \\
& =\left[\begin{array}{c}
0.1417 \\
-0.0857
\end{array}\right] \text {, }
\end{aligned}
$$

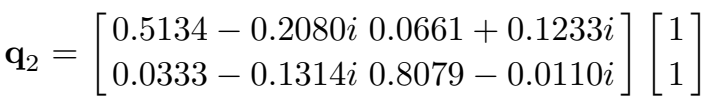

$$
\begin{aligned}
& =\left[\begin{array}{l}
0.5795-0.0847 i \\
0.8412-0.1424 i
\end{array}\right] \text {. }
\end{aligned}
$$

dan

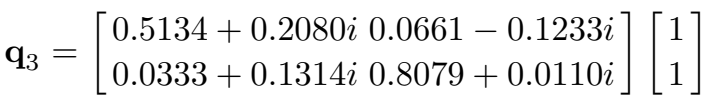

$$
\begin{aligned}
& =\left[\begin{array}{l}
0.5795+0.0847 i \\
0.8412+0.1424 i
\end{array}\right] \text {. }
\end{aligned}
$$

Selanjutnya substitusikan $\mathbf{q}_{1}, \mathbf{q}_{2}$, dan $\mathbf{q}_{3}$ ke (2.14), diperoleh

$$
Q=\left[\begin{array}{ccc}
0.1417 & 0.5795-0.0847 i & 0.5795+0.0847 i \\
-0.0857 & 0.8412-0.1424 i & 0.8412+0.1424 i
\end{array}\right] .
$$

Karena $\operatorname{rank}(V)=3$ dan matriks

$$
V^{-1}=\left[\begin{array}{cc}
3.8217+0.0000 i & 1.7366+0.0000 i-21.3161-0.0000 i \\
-0.0420+2.0470 i & 2.0097+2.2765 i-7.8046-20.5833 i \\
-0.0420-2.0470 i & 2.0097-2.2765 i-7.8046+20.5833 i
\end{array}\right],
$$


maka diperoleh matriks feedback $F$ yang menstabilkan sistem (2.16), yaitu

$$
F=\left[\begin{array}{lll}
0.8396 & 2.9610-15.5528 \\
0.1848 & 3.8806-17.1658
\end{array}\right] .
$$

\section{Kesimpulan}

Diberikan sistem kontrol linier invariant waktu dalam bentuk

$$
\dot{\mathbf{x}}=A \mathbf{x}+B \mathbf{u} .
$$

Sistem kontrol linier invariant waktu yang tidak stabil dikatakan dapat distabilkan jika terdapat kontrol $\mathbf{u}=-F \mathbf{x}$ untuk suatu $F \in \mathbb{R}^{m \times n}$ sedemikian sehingga sistem loop tertutup $\dot{\mathbf{x}}=(A-B F) \mathbf{x}$ adalah stabil, artinya matriks $F$ dipilih sedemikian sehingga bagian riil dari semua nilai eigen matriks $A-B F$ adalah negatif.

Proses stabilisasi dengan penempatan nilai eigen sesuai keinginan dapat dilakukan jika sistem kontrol linier invariant waktu adalah terkontrol keadaan lengkap dan matriks feedback $F$ memenuhi

$$
F M^{i} \mathbf{r}_{i}=D^{i} \mathbf{r}_{i}, \quad i=1,2, \cdots, n .
$$

\section{Ucapan Terima kasih}

Penulis mengucapkan terima kasih kepada Bapak Dr. Muhafzan, Ibu Arrival Rince Putri, M.T, M.Si, Bapak Dr. Admi Nazra, Bapak Drs. Syafruddin M.Si dan Ibu Nova Noliza Bakar, M.Si yang telah memberikan masukan dan saran sehingga paper ini dapat diselesaikan dengan baik.

\section{Daftar Pustaka}

[1] Anton, H. dan C. Rorres. 1991. Aljabar Linier Elementer Edisi 8 Jilid 1. Erlangga, Jakarta.

[2] Antsaklis, P.J. dan A.N. Michel. 2007. Linear Systems. Birkhauser, Boston.

[3] Hendricks,Elbert, Ole Jannerup, Paul Haase Sorensen. 2008. Linear System Control. Springer, Verlag Berlin Heidelberg.

[4] Jacob, B. 1990. Linear Algebra 1. Freeman, W.H. and Company. New York.

[5] Ogata, K. 2002. Modern Control Engineering, Fourth Editon. Prentice-Hall, New Jersey. 